Egyptian Journal of Rabbit Science, 30(2): 111- 123 (2020)

\title{
GENETIC PARAMETERS OF BODY WEIGHT AND MEASUREMENTS TRAITS IN BALADI BLACK RABBITS
}

M. G. Gharib; Amira S. El-Deighadi; M. I. saf Al-Nasr; Yonan G. E.; Mogda M. Salem and Lamiaa, F. Abdel -Mawla

Animal Production Research Institute, Agriculture Research Center, Dokki, Cairo, Egypt (APRI), e.mail: mghreeb95@yahoo.com

ABSTRACT: A total of 250 progeny of 17 sires and 58 dams from Baladi Black breed population were used to estimate variance components and heritability of growth traits. Traits studied were individual body weight (BW12), body length (BL12), head length (HL12) and thigh circumference (TC12) all at 12 weeks of age. Single-trait Animal Model (DFREML) was used to estimate genetic variance components, as well as permanent environmental variation. Estimates of variance components were 0.52, 0.96, 0.91 and 0.81 for BW12, BL12, TC12 and HL12, respectively. Heritability estimates were $0.24,0.36,0.36$ and 0.33 for BW12, BL12, TC12 and HL12 respectively. The proportions of variance due to permanent environmental effect of dams were $0.08,0.05,0.10$ and 0.12 for BW12, BL12, TC12 and HL12, respectively.
Results showed that out of the principal components (PC) calculated, the one represent 68.98 $\%$ of the total variance. The PC1 was 68.98 of the generalized variance. Principal component factor scores expound $77 \%$ of the variation in the body weight of rabbits.

Conclusively, the use of orthogonal body shape characters (PC1) derived from the principal component factor solution could be more reliable in predicting body weight compared to the use of the original autocorrelated body measurements. This is because multicollinearity of interdependent explanatory variables could lead to false inferences when original body measurements are used as predictors.

Key words: Body measurements, multicollinearity, Rabbits, Principal Component Analysis.

\section{INTRODUCTION}

Heritability offers the knowledge of genetic status for traits and is required for genetic evaluation and determining selection strategies (El-Raffa 
et al., 2005). Therefore, the efficiency of rabbit production counts basically on the heritability estimate of the traits and the link between this trait and other traits of economic importance. However, knowing the available sources of random environmental variation that affect growth, and can be controlled by management, is also needed to estimate accurately measure and the amount of genetic variation that can be used through selection in rabbit populations (Amira El-Deighadi, 2005). Therefore, having the estimates of permanent environmental and/or common litter effects in model for analysis of postweaning growth and conformational traits would leads to accurate and good estimation of the direct genetic effect due to that they are associated, in most cases, with considerable decrease in value or $\%$ of the error term (Youssef et al., 2009). Principal component analysis (PCA) helps to decrease the number of variables under analysis to a smaller number of factors and to disassemble multicollinearity among them (Constantin, 2014).

Independent variable scores from PCA to predict body weight and some different body morphmetric traits have been used by many research (e.g. Ajayi and Oseni, 2012; Udeh, 2013; Akinsola et al., 2014; Egena et al., 2014 and Gouda et al., 2015).

Therefore, the objective of this present study was carried out to estimate some genetic parameters that influence body weights and body conformation measurements, as well as, providing principal components estimates of the predicted body weight of Baladi Black rabbit's at12 weeks of age.

\section{MATERIALS AND METHODS}

\section{Animals and data:}

This study was carried out during two successive years at Sakha Animal Farm, Animal Production Research Institute (APRI), Agricultural Research Center, Dokki, Egypt. Data collected on 250 progeny rabbits resulted from 17 sires and 58 dams from the local Egyptian rabbit breed Baladi Black (BB). In all applied matings, according to the breeding plan, a buck was assigned at random for every 3-4 does with a restriction of avoiding full sib, half sib and parent-offspring matings.

Data of body weight and body Linear measure traits at 12 weeks of age were analyzed using single-trait animal model DF-REML program of Boldman et al., (1995) according to the following animal model:

Where:

$$
\mathrm{Y}=X \boldsymbol{b}+Z_{a} u_{a}+Z_{\mathrm{c}} u_{\mathrm{c}}+e
$$


Y Column vector of observational trait on the evaluated animals;

$b \quad=$ Column vector of fixed effects (i.e. parity and sex);

$u_{a} \quad=$ Column vector of random animal effects;

$u_{c} \quad=$ Column vector of random common litter effects;

$e \quad=$ Column vector of random residual effects;

$X, Z_{a}$ and $Z_{c}$ are incidence matrices relating records to fixed, animal and common litter effects, respectively.

The single-trait animal model was used to estimate proportions of additive genetic, common litter, error and phenotypic variance, as well as heritability, $\left(\mathrm{h}_{\mathrm{a}}^{2}\right)$ and breeding values for body weight and body Linear measure traits at 12 weeks of age.

\section{Linear measures data:}

Body Length (BL12), Thigh Circumference (TC12) and Head Length (HL12) at 12 weeks of age were measured applying the following protocol, BL12 = distance from the point of the shoulder to the pin bone (Tuber ischi), TC12 = circumference at the knee-cap (patella), HL12 = distance from in-between the ears to the tip of nose.

These linear measures data were utilized as predictors of expected body weight at 12 weeks of age, using SPSS 16 (2007) according to the following multiple linear regression model of:

Where:

$$
\mathrm{Y}=\mathrm{a}+\mathrm{b}_{1} \mathrm{X}_{1}+\mathrm{b}_{2} \mathrm{X}_{2}+\ldots \ldots . .+\mathrm{b}_{\mathrm{p}} \mathrm{X}_{\mathrm{p}}+\mathrm{e}
$$

$\mathrm{Y}=$ the dependent variable $(\mathrm{BW} 12) ; \mathrm{a}=$ intercept $/$ constant; $\mathrm{X}_{\mathrm{p}}=$ the $\mathrm{p}^{\text {th }}$

Independent/predictor variable BL12, TC12 and HL12; $b_{1}, b_{2}$, $\ldots, b_{\mathrm{P}}=$ the $\mathrm{p}^{\text {th }}$ partial regression coefficients of $\mathrm{Y}$ on $\mathrm{Xp}$ 's; and $\mathrm{e}=$ error.

\section{Principal components analysis (PCA):}

SPSS 16 (2007) statistical package were used for calculation of principal component analysis. Data for PCA were generated from the correlation matrix. Anti-image correlations, Kaiser-Meyer-Olkin, 1960 (measures of sampling adequacy) and Bartlett's test (test the null hypothesis that the original correlation matrix is an identity matrix) were computed to test the validity of the factor analysis of the data sets. BW12 was predicted from linear body measurements and from principal component factor scores with varimax rotation by using the following stepwise multiple regression models: 


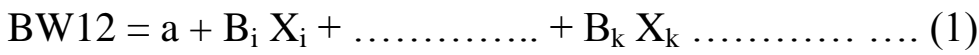

$B W 12=a+B_{i} P_{i}+\ldots \ldots \ldots . .+B_{K} P_{K}+\ldots \ldots \ldots . .(2)$

Where: BW12 is body weight at 12 weeks of age, a is the regression intercept, $B_{i}$ is the $i^{\text {th }}$ partial regression coefficient of the $i^{\text {th }}$ linear body measurements (Xi) or the $i^{\text {th }}$ principal component (PCi).

\section{RESULTS AND DISCUSSION}

Means, standard deviations and coefficients of variation (CV \%).

Means for body weight (BW12), body length (BL12), thigh circumference (TC12) and head length (HL12) for rabbits at 12 weeks of age are presented in Table 1. Results of present study were within the ranges observed by Faten El-Badawy et al., (2013) and Fatma Behiry (2014).

The relatively reduced body weight in this study compared to related traits found in other temperate regions may be due to inappropriate environmental factors, such as humidity, temperature and feed supply (Shahin and Hassan, 2000).

Estimates of CV\% traits were not consistent and slightly low, similar results were reported by Attalah, (2007); Hassanein,( 2011); Faten El-Badawy et al., (2013) and Fatma Behiry,(2014). This trend might be due to the consequence of the expression of combination of non-genetic maternal environment and the genetic factors (Falconer, 1989).

Table 1. Overall means and standard deviations (CV \%) of BW12, BL12, TC12 and HL12 traits of Baladi Black rabbits at 12 weeks of age.

\begin{tabular}{lccc}
\hline Traits & Mean & SD & CV\% \\
\hline BW12 & 1240.61 & 277.11 & 22.32 \\
BL12 & 29.10 & 2.63 & 7.10 \\
TC12 & 12.10 & 1.68 & 13.88 \\
HL12 & 8.68 & 1.55 & 17.88
\end{tabular}

+ BW12 = Body weight, BL12 = Body length, TC12 = Thigh circumference and HL12 = Head length.

\section{Additive genetic Variance $\left(\sigma_{a}^{2}\right)$ :}

The additive genetic variance $\left(\sigma_{a}^{2}\right)$ and its percentage contribution to the variation for BW12, BL12, TC12 and HL12 at 12 weeks of age traits were presented in Table, 2. The $\sigma^{2}{ }_{\mathrm{a}} \%$ ranged between low to moderate and was 
Table 2. Variance components $\left(\mathrm{V}_{\mathrm{a}}, \mathrm{V}_{\mathrm{c}}, \mathrm{V}_{\mathrm{e}}\right.$ and $\left.\mathrm{V}_{\mathrm{p}}\right)$, heritability $\left(\mathrm{h}^{2}{ }_{\mathrm{a}}\right)$, common litter effect $\left(\mathrm{c}^{2}\right)$ and error $\left(\mathrm{e}^{2}\right)$ for BW12, BL12, TC12 and HL12 traits of Baladi Black rabbits at 12 weeks of age.

\begin{tabular}{|lcccc|}
\hline & BW12 & BL12 & TC12 & HL12 \\
\hline $\mathrm{V}_{\mathrm{a}}$ & 0.51857 & 0.95850 & 0.91236 & 0.81237 \\
$\%$ & 23.6 & 34.9 & 35.8 & 32.7 \\
$\mathrm{~V}_{\mathrm{c}}$ & 0.18575 & 0.14837 & 0.25747 & 0.294838 \\
$\%$ & 8.4 & 5.5 & 10.2 & 12.1 \\
$\mathrm{~V}_{\mathrm{e}}$ & 1.49495 & 1.63854 & 1.36985 & 1.36985 \\
$\%$ & 68 & 59.6 & 54.5 & 55.2 \\
$\mathrm{~V}_{\mathrm{p}}$ & 2.19927 & 2.74541 & 2.53968 & 2.47706 \\
$\mathrm{~h}^{2}$ & $0.24 \pm 0.01$ & $0.36 \pm 0.143$ & $0.36 \pm 0.21$ & $0.33 \pm 0.25$ \\
$\mathrm{C}^{2}$ & $0.08 \pm 0.02$ & $0.05 \pm 0.034$ & $0.10 \pm 0.06$ & $0.12 \pm 0.07$ \\
$\mathrm{e}^{2}$ & $0.68 \pm 0.01$ & $0.60 \pm 0.139$ & $0.54 \pm 0.19$ & $0.56 \pm 0.23$ \\
\multicolumn{4}{l}{$\mathrm{V}_{\mathrm{a}}, \mathrm{V}_{\mathrm{c}}, \mathrm{V}_{\mathrm{e}}$ and $\mathrm{V}_{\mathrm{p}}=$ additive, common litter effect, error and phenotypic variance, } \\
respectively. & + Traits as defined in Table 1.
\end{tabular}

$23.6 \%, 34.9 \%, 35.8 \%$ and $32.7 \%$ for BW12, BL12, TC12 and HL12, respectively, for traits study, the same trend was observed by (Khalil et al., 2000; Hassan, 2004 and Youssef, 2004).

Attalh et al., (2007) reported that $\sigma 2 \mathrm{a} \%$ in BL12 trait, due to the sire effect, were somewhat low in Bauscat and Baladi Red rabbits. Faten ElBadawy et al., (2013) with Baladi Black rabbits found that $\sigma 2$ a was 0.37, 0.02 and $0.18 \%$ for BW12, BL12 and TC12 at 12 weeks of age, respectively.

\section{Heritability $\left(\boldsymbol{h}^{2}\right.$ )}

Heritability estimates for BW12, BL12, TC12 and HL12 at 12 weeks of age traits were highly moderate and were $0.24,0.36,0.36$ and 0.33 respectively in Table 2. Similar to these estimates observed by (Attalah et al., 2007; Youssef et al., 2009; Hassanein, 2011 and Elamin et al.,2012).

Faten El-Badawy et al., (2013) with Baladi Black rabbits found that $\mathrm{h}^{2}{ }_{\mathrm{a}}$ estimates was 0.37 and 0.17 for BW12 and TC12 at 12 weeks of age, respectively. Fatma Behiry (2014) with Baladi Red rabbits found that $\mathrm{h}^{2}{ }_{\mathrm{a}}$ estimates was $0.26,0.05$ and 0.37 for BW12, BL12 and TC12 at 12 weeks of age. Moderate heritabilities obtained for traits studied might indicate that improvement of body weight could possibly be achieved through selection (Amira El-Deighadi et al., 2017). High values of heritability indicates that, trait's phenotype is, to certain degree, good indicator of underlying breeding values (Farghaly and El-Mahdy, 1999). Therefore, phenotypic selection, at 
that age, would be effective for high body weights response in these rabbits' strains.

\section{Common litter effect $\left(c^{2}\right)$}

Common litter effect $\mathrm{c}^{2}$ of body weight was low 0.05 to moderate 0.12 in Table 2. The same conclusion was noticed by (Youssef et al., 2009; Hassanein, 2011 and Hassan et al., 2013). However, these results were smaller than those observed by (Faten El-Badawy et al., 2013; Fatma Behiry, 2014 and Amira El-Deighadi et al., 2017). Common litter influences may be in some cases, more important than additive genetic effects of post weaning growth in rabbits (Iraqi, 2008).

In general, the small values of $c^{2}$, though expected, might be attributed partially to a large temporary environmental variation (included sanitary and managerial conditions etc...) which could not be considered in the statistical models (Moura et al., 1991).

Youssef et al., (2009) reported that $\mathrm{c}^{2}$ effect could be accounted for common maternal environmental variation, non-additive genetic variation and any sire $\mathrm{x}$ dam interaction that may present, since this component largely represented covariance between full-sibs families. In addition to that, another source of common maternal environmental variance between families may be due to nutritional and climatic factors or both.

\section{Predicted breeding value (BV):}

Estimates of minimum and maximum all progeny (PBV), Sire (SBV) and dam (DBV) breeding values for BW12, BL12, TC12 and HL12 traits are given in Table 3 .

The estimates of PBV ranged from 2.530 to $5.206 \mathrm{~cm}$, while SPV from 1.814 to $3.921 \mathrm{~cm}$, however, DBV from 1.648 to $3.397 \mathrm{~cm}$. Similar estimates to these were reported by Hassanein, (2011); Hassan et al.,( 2013); Faten El-Badawy et al., (2013); Fatma Behiry, (2014) and Amira El-Deighadi et al., (2017). Faten El-Badawy, (2013) with Baladi Black rabbits found that PBV ranged between 6.08 to 7.48, while SBV ranged from 2.24 to 4.38 for BW12, BL12, and TC12 traits at 12 weeks of age, respectively. Fatma Behiry, (2014) observed that PBV were ranged from 6.08 to 7.48, while SBV ranged from 2.24 to 4.38 for $\mathrm{BW} 12, \mathrm{BL} 12$, and TC12 traits at 12 weeks of age respectively. 
Table 3. Progeny, sire and dam breeding values (BV), standard error (SE), accuracy (r) and ranges of BW12, BL12, TC12 and HL12 traits of Baladi Black rabbits at 12 weeks of age.

\begin{tabular}{llllllll}
\hline \multirow{2}{*}{ Traits } & \multicolumn{9}{c}{ Minimum } & \multicolumn{3}{c}{ Maximum } & \multirow{2}{*}{ Ranges } \\
\cline { 2 - 6 } & BV & SE & \multicolumn{1}{c}{ r } & BV & SE & r & \\
\hline BW12 & -1.427 & 0.80 & 0.65 & 2.506 & 0.81 & 0.63 & 3.933 \\
BL12 & -2.160 & 0.76 & 0.64 & 3.046 & 0.78 & 0.60 & 5.206 \\
TC12 & -1.427 & 0.80 & 0.65 & 2.506 & 0.81 & 0.63 & 3.933 \\
HL12 & -1.561 & 0.74 & 0.63 & 0.969 & 0.76 & 0.60 & 2.530 \\
BW12 & -1.337 & 0.80 & 0.65 & 1.417 & 0.90 & 0.51 & 1.754 \\
BL12 & -1.571 & 0.68 & 0.72 & 2.35 & 0.85 & 0.49 & 3.921 \\
TC12 & -1.337 & 0.80 & 0.65 & 1.417 & 0.51 & 0.51 & 2.754 \\
HL12 & -1.139 & 0.71 & 0.66 & 0.675 & 0.67 & 0.71 & 1.814 \\
BW12 & -0.930 & 0.78 & 0.67 & 0.727 & 0.78 & 0.67 & 1.657 \\
BL12 & -1.719 & 0.76 & 0.64 & 1.678 & 0.69 & 0.67 & 3.397 \\
TC12 & -0.921 & 0.78 & 0.67 & 0.727 & 0.78 & 0.67 & 1.648 \\
HL12 & -1.370 & 0.72 & 0.66 & 0.990 & 0.74 & 0.63 & 2.360 \\
\hline
\end{tabular}

+ Traits as defined in Table 1 .

\section{Principal component analysis (PCA):}

The principal component matrix for body measurements (BL12, TC12 and HL12) in Baladi Black (BB) rabbits are presented in Table 4. After varimax rotation, principal component weights derived from the correlation matrix of the three body measurements the variance percent explained by each of the first three PCA's were $68.983 \%, 22.483 \%$, and $8.535 \%$, respectively. These coefficients showed that, one principal component with eigenvalue greater than one, and explained $68.983 \%$ of the total variance (Table 4). Similar results were reported by (Udeh, 2013) who, found one principal component with eigenvalue greater than 1 and explained $77.23 \%$ of the total variance. Imilar models were also reported by many authors (e.g. Yakubu and Ayoade, 2009 and Akinsola et al., 2014).

Yakubu and Ayoade, (2009) observed that two principal components (PC1 and PC2) obtained up to $90.27 \%$ of the total variance. PC1 was highly correlated with BL12 and TC12 while PC2 was associated with ear length. The authors concluded that PC1 was a good predictor of body weight.

The PC scores for each animal was calculated as:

$$
\mathrm{PC} 1=0.420 \mathrm{BL} 12+0.438 \mathrm{TC} 12+0.340 \mathrm{HL} 12
$$


Table 4. The eigenvalues, variance and cumulative variance $\%$ by different components (PC) of BL12, TC12 and HL12 traits in Baladi Black rabbits.

\begin{tabular}{lccc}
\hline & \multicolumn{3}{c}{ Initial Eigenvalues } \\
\cline { 2 - 4 } PC & Total & \% of Variance & Cumulative \% \\
\hline 1 & 2.069 & 68.983 & 68.983 \\
2 & 0.674 & 22.483 & 91.466 \\
3 & 0.256 & 8.534 & 100.00 \\
\hline
\end{tabular}

The PC factor was due to use of the genetic values that would clear up most BW12 increasing would which be expected to increase with increasing PC1. Multicollinearity problem could be solved with the prediction of BW12 during other independent variables. These results confirmed by (Shahin and Hassan, 2000; Shahin and Hassan, 2002 and Akinsola et al., 2014).

\section{Prediction of body weight:}

The interdependent conformation $\left(\mathrm{R}^{2}\right)$ for traits and their independent fact scores were used to predict body weight of rabbits in Table 5. Thigh circumference alone explained about $75 \%$ of the variation of body weight. hen Body length was added to the model, the proportion of explained variance increased to $83 \%$. This result indicates that body weight can be predicted with a fair degree of accuracy from body dimensions. Similar findings have been reported by other workers (Shahin and Hassan, 2000 and Udeh, 2013).

However, using body measurements to predict body weight/growth should be treated with caution due to multicollinearity, which has been shown to be associated with unstable regression estimates (Ibe, 1989), thereby, leading to unreliable predictions. This justified the use of indices of the body measurements, referred to as principal components for prediction, since they are orthogonal to each other. In this wise, PC1 contributed to about $75 \%$ of the total variation in body weight when used as a sole predictor. All the regression models were significant at $(\mathrm{P}<0.01)$. Shahin and Hassan, (2000), with Baldi Balck rabbits, BL12 seems to be the major trait in determining live weight. The results of regression analysis for predicting live weight from body dimensions showed that BL12 alone accounted for $74.4 \%$ of the variation in live body weight. Coefficient of determination $\left(\mathrm{R}^{2}\right)$ was rogressively improved to 0.90 when thigh circumference and chest width were added. 


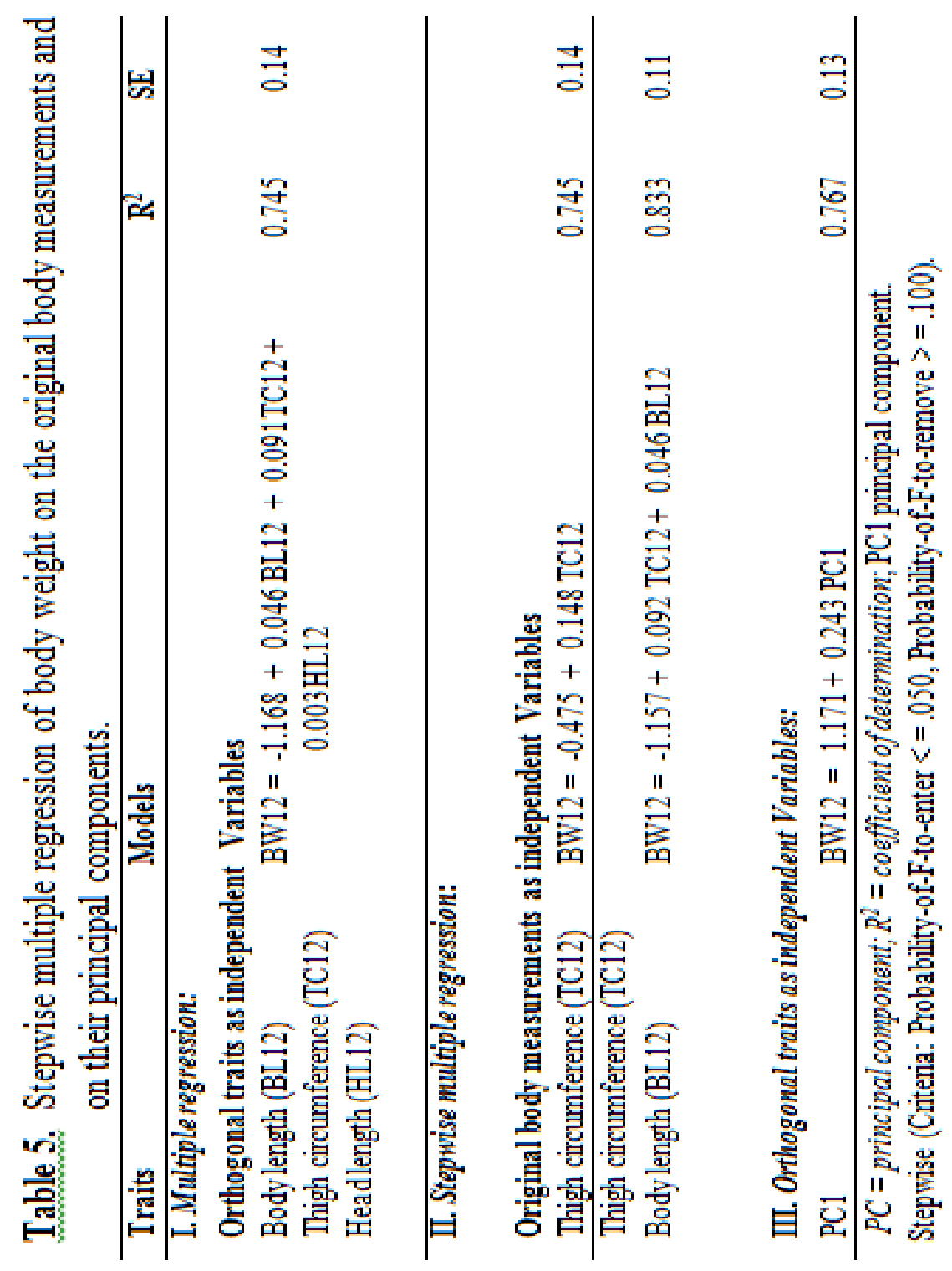


Also, the same author reported that PC1 and PC2 independent confirmation traits derived from factor analysis accounted for $90.8 \%$ of the variation in live body weight in BB rabbits. Akinsola et al., (2014), reported that the Hyla rabbits, PC1 and PC2 independent confirmation traits derived from factor analysis accounted for $88 \%$ of the variation in live body weight.

\section{CONCLUSION}

The present principal component analysis provided a means for objective description of the interdependence in the original four body measurements of rabbits. Using of orthogonal body shape characters (PC1) derived from the principal component factor solution could be more reliable in predicting body weight compared to the use of the original intercorrelated body measurements. This is because multicollinearity of interdependent explanatory variables could lead to false inferences when original body measurements are used as predictors.

\section{REFERENCES:}

Ajayi, B. O. and Oseni, S. O. (2012). Morphological characterisation and principal component analysis of body dimensions in nigerian population of adult rabbits. Proceedings 10th World Rabbit Congress, 3-6 September. Sharm El-Sheikh, Egypt,. pp: 229-233.

Akinsola, O. M., Nwagu, B. I.; Orunmuyi, M.; Iyeghe-Erakpotobor, G. T.; Eze, E.D.; Abanikannda, O. T. F.; Onaadepo, O.; Okuda, E. U. and Louis, U. (2014). Prediction of bodyweight from body measurements in rabbits using principal component analysis. Annals of Biological Sciences, 2 (1):1-6.

Amira El-Deighadi, A. (2005). Genetic evaluation for some productive traits in rabbits. Ph.D. Thesis, Fac. Agric., Moshtohor, Zagazig Univ., Banha Branch, Egypt.

Amira El-Deighadi, A. and M. K. Ibrahim. (2017). Genetic aspects of post-weaning for growth traits in new zealand white rabbits. Egyptian Journal of Rabbit Science, 27 (2): 507- 521.

Attalah, G. E. Y.; Farid, A. M. and Gharib, M. G . (2007). Factors effecting weaning and post-weaning body measurement in Bauscat, and Baladi Red rabbits. Al-Azhar J. Agric. Res., 2: 149-168. 
Boldman, K G, Kriese, L. A., Van Vleck, L. D.; Van Tassell, C. P. and Kachman S D (1995). A manual for use of MTDFREML. A set of programs to obtain estimates of variances and covariances [DRAFT]. U.S., Department of Agriculture, Agricultural Research Service, USA.

Constantin, C. (2014). Principal component analysis-a powerful tool in computing marketing information. Bulletin of the Transilvania University of Braşov. Series V: Economic Sciences, 7 (56), No. 2.

Egena, S. S. A.; Akpa G. N.; Aremu, A. and Alemede, I. C. (2014). Sources of shared variability in body weight and linear body measurement traits of two breeds of rabbit. International Journal of Plant, Animal and Environmental Sciences, 4 (2): 141-145.

Elamin, K. M.; Yousif, I. A.; Ahmed, M. K. A.; Mohammed, S. A. and Tameen Eldar, A.A. (2012). Estimation of genetic, phenotpice and environmental parameters of morphometric traits in Sudanese rabbits. Asian Journal of Animal Science, 6 (4): 174-I81.

El-Raffa, A. M. (2005). Genetic and non-genetic relationships between growth performance and litter size traits in a maternal rabbit line. Egypt. Poult. Sci., 25: 1203-1215.

Falconer, D. S. (1989). Introduction To Quantitative Genetic. Third Edition, Longman, UK.

Farghaly, H. M. and El-Mahdy, M. R. M. (1999): Genetic and non-genetic factors affecting live, carcass and non carcass traits of New Zealand White rabbits in Egypt. Indian J. Anim. Sci., 69 (8): 596-603.

Faten El-Badawy; Hassan, N. S.; El-Gendy, E. A. and Stino , F. K. (2013). Genetic aspects in some growth \& measurements traits in rabbits. Egyptian Journal of Rabbit Science, 23 (2): 123 - 135.

Fatma Behiry (2014). Genetic study for some body measurements and its relationship with some productive traits in rabbits. Ph.D. Thesis, Department of Animal Production, Faculty of Agriculture, Tanta Univ., Egypt

Gouda, G.F.; Shemeis, A.R. and O.Y. Abdallah (2015). Prediction of total muscle weight from morphometric live traits in rabbits using principal component analysis. Egyptian Journal of Rabbit Science, 25(2): $185-196(2015)$

Hassan, N.S. (2004). New Zealand White rabbits' BLUP values for postweaning individual body weight under Egyptian conditions. 8th World Rabbit Congress, September 7-10, 2004 - Puebla, Mexico. 
Hassan, N. S.; Abd El-Ghany, A. M.; Hanan ,H.; Ghanem, M. A.; ElShennawy and Mona, M. Ghaly, (2013). Genetic Evaluation of The Native Baladi Black Rabbits Under North Delta Weather of Egypt Using Animal Model Procedure. A: Doe Litter Traits. Journal of Animal, Poultry \& Fish Production, 1:13-22.

Hassanein, E. A. (2011). Genetic studies on rabbits. Ph.D. Thesis, Fac. of Agric. Al-Azhar Univ. Egypt.

Ibe, S. N. (1989). Measures of size and conformation in commercial broilers. J. Anim. Breed. Genet., 106:461-9, 1989.

Iraqi, M. M. (2008). Estimation of Genetic parameters for post-weaning growth traits of Gabali rabbits in Egypt. Livestock Research for Rural Development , 20 (5), 2008

Kaiser, H. F. (1960). The Application of Electronic Computers to Factor Analysis. Educ Psychol Meas. 1960; 20: 141-151.

Khalil, M. H.; Ibrahim, M. K.; Youssef, Y. M. K. and El-Deighadi, A. S. (2000). Estimation of sire transmitting abilities for post-weaning growth traits in New Zealand White and Californian rabbits raised in adverse hot climatic Egyptian conditions using an animal model. Egyptian Poultry Science, 20(1): 65-90

Moura, A.S.A.M.T., Polastre, R. and Nunes J. R. V. (1991). Genetic study of litter traits at weaning in selection rabbits. J. Appl. Rabbit Res., $14,222-227$.

Shahin, K. A. and Hassan, N. S. (2000). Sources of shared variability among body shape characters at marketing age in New Zealand White and Egyptian rabbit breeds. Annales de Zootechnie, 49: 435-445.

SPSS. (2007). Statistical Package for the Social Sciences. SPSS Inc., Chicago, SPSS Inc., 444 Michigan Avenue, IL60611.

Udeh, I. (2013). Prediction of body weight in rabbits using Principal Component Factor Scores in Multiple Linear Regression Model Rabbit Genetics, 3 (1): 1-6.

Yakubu A. and Ayoade J. A. (2009). Application of principal component factor analysis in quantifying size and morphological indices of domestic rabbits. Int J Morphol., 27(4):1013-1017.

Youssef, Y. M. K. (2004). Heritabilities and common litter effects estimated by animal model for post-weaning growth traits in New Zealand White and Baladi Red rabbits. Egypt. Poultry. Sci., Vol. 24(1): 205216. 
Youssef, M. K.; Farid, A.; Gad-Alla, S. A. and Abo-Warda, M. A. (2009). Genetic evaluation for post weaning body weight traits in three genetic groups of rabbits under Egyptian conditions. The 5th Inter. Poultry Con., Taba, Egypt.

\section{المقاييس الوراثية لوزن ومقاييس الجسم في أرانب البلاى الأسود}

محمود غريب غريب رأميرة سليمان الدغيدى , محمد إبراهيم عبدالنبى سيف النصر ,

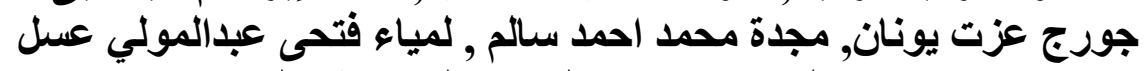

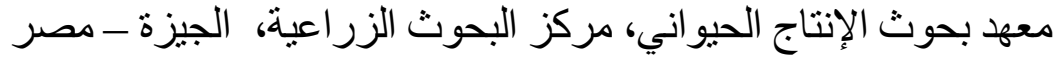

استخدمت بيانات 250 ارنب مفطوم من 19 ذكر و58 امث من من سلالة البلدي

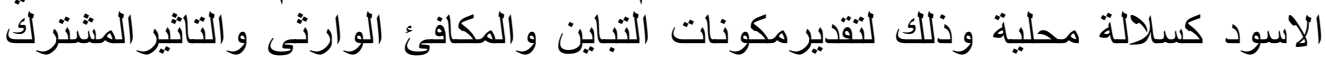

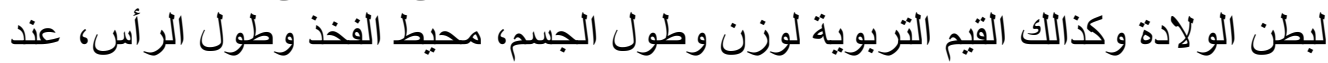
عمر 12 أسبوع حيث تم تحليل البيانات باستخدام النموذج الحئ الحيو انى أحادى الصفة. وقد أوضحت الدراسة النتائج آلاتية-:

كانت تقديرات مكونات التباين التهاتئ 0.52، 0.96،

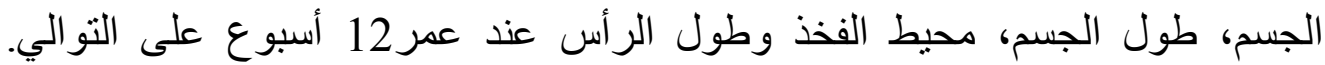

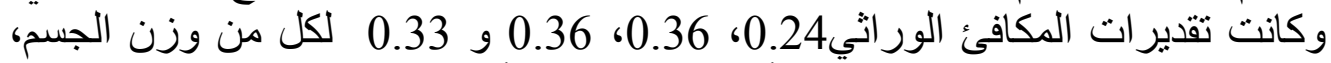

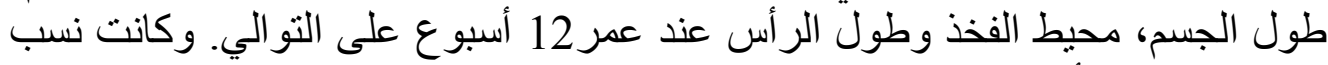

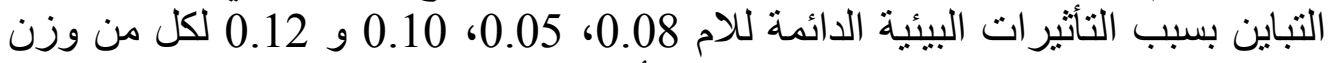

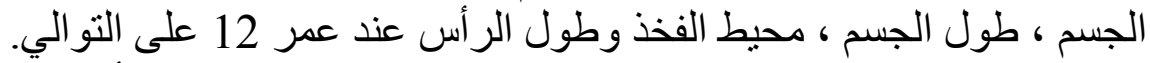

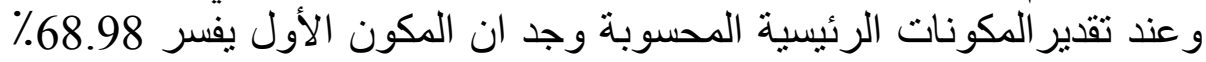

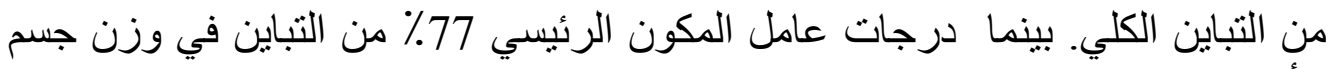

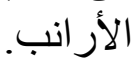
التوصية : تطبيق تحليل المكونات الاساسية يكون مفيد افى استبعاد الارنباطات الخطية

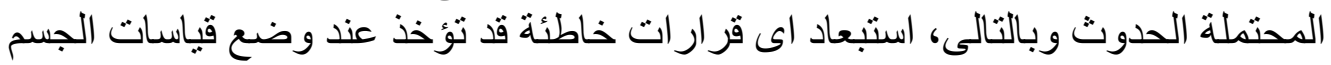
الخارجية مع بعضها البعض فئى الانحدار المتعدد. 